\title{
Effect of Orlistat on blood pressure in overweight/obese hypertensive patients
}

\author{
Sudhir Kumar Verma ${ }^{1}$, Arvind Kumar Vaish ${ }^{2}$, Ram Milan Prasot ${ }^{3}$ \\ ${ }^{1}$ Assistant Professor, Department of General Medicine, Career Institute of Medical Sciences, Lucknow, India \\ 2.Professor and Head,Department of General Medicine, King George's Medical University, Lucknow, India \\ ${ }^{3}$ Assistant Professor, Department of Community Medicine, Career Institute of Medical Sciences, Lucknow, India
}

Abstract: Background: Obesity is an emerging public health problem, associated with an increased risk of serious medical illnesses including hypertension. Behavioral therapy alone has limited role in providing significant and sustained weight loss. If Orlistat, an anti-obesity drug is adequate enough to cause significant decrease in blood pressure, the cost and potential adverse affects of lifelong drug therapy can be avoided. Objectives: To determine the effect of Orlistat on blood pressure in overweight/obese hypertensive patients. Materials and methods: A prospective randomized, open double-blinded study was conducted in a tertiary care hospital. Patients with body mass index $\geq 23$ with essential hypertension with diastolic blood pressure between 90 to $100 \mathrm{mmHg}$, who were not on any antihypertensive treatment were selected for this study. Patients were randomly divided into two groups - group I which received Orlistat and group II which received placebo only along with similar hypo-caloric diet in both groups. The patients were serially followed for up to 3 months for change in blood pressure, weight, lipid profile, blood sugar and waist hip ratio.

Results: We observed significant reduction in blood pressure, weight, blood sugar, lipid profile and waist hip ratio in group I as compared to group II.

Conclusion: We conclude that, Orlistat in combination with diet restriction significantly improve blood pressure in obese hypertensive patients as compared to placebo.

Keywords: Obesity, hypertension, anti-obesity drugs

\section{Introduction}

Obesity is a state of excess fat accumulation that is causally related to serious medical illnesses and economic burden on society. It is a leading preventable cause of death worldwide.

According to a global estimate by the World Health Organization (WHO), in 2005 there were about 1.6 billion overweight persons aged 15 years and above and among them at least 400 million adults were obese. ${ }^{1}$ The WHO further projects that by 2015, approximately 2-3 billion adults will be overweight and more than 700 million will be obese. ${ }^{1}$ Hypertension is one of the most common obesity-related complications, and about $30 \%$ of hypertensive individuals can be classified as being obese. ${ }^{2}$

Results from the Framingham Study have shown that high blood pressure and overweight are both independent risk factors for cardiovascular diseases. ${ }^{3,4}$ In INTERSALT study ${ }^{5}$, the relationship between body mass index (BMI) and blood pressure was studied in over 10,000 men and women, between 20 and 59 years of age, sampled from 52 centres around the world. In this large study population, BMI was significantly associated with systolic and diastolic blood pressure.

Weight loss has been recommended for the obese hypertensive patient. Behavioral therapy alone has limited success in providing significant and sustained weight loss, which prompted us to conduct this study. Even a modest weight loss produces a positive effect on obesity-related complications including hypertension. If only anti-obesity drug treatment is adequate enough to normalize blood pressure, the cost and potential adverse affects of drug therapy can be avoided.

\section{Materials and Methods}

The study was conducted in department of General Medicine, King George's Medical University, Lucknow, India between August 2008-October 2009. The study was a prospective randomized open blinded evaluation (PROBE) design.

Patients between 20 to 60 years of age with body mass index $\geq 23$ with essential hypertension with diastolic blood pressure between 90 to $100 \mathrm{mmHg}$, who were not on any antihypertensive treatment were selected for this study.

Patients with endocrinal disorders, renal or hepatic disease, malignancy, medications known to alter blood pressure,body weight or appetite, pregnant and lactating women, severely ill patients and patients not giving consent were excluded from the study 
Detailed history regarding complaints, duration, drugs being presently taken, any previous history of hypertension, diabetes mellitus, smoking status, family history of hypertension was carefully elicited in all cases.

A detailed clinical examination was carried out in all the cases. Blood pressure (left arm sitting position), weight, body mass index and waist/hip rate was measured carefully.

Following investigations were carried out:

1. Hemogram

2. Urine: Routine and microscopic

3. Blood sugar: Fasting and postprandial

4. Serum urea and creatinine

5. Serum lipid profile

Cases were randomly categorized into 2 groups:

Group I: This group received Orlistat $120 \mathrm{mg}$ twice daily.

Group II: This group received placebo twice daily.

A similar dietary chart and dietary advice (hypo-caloric diet - $600 \mathrm{kcal} /$ day deficit) was given to both groups.

Patients were continued on these therapies for three months. Compliance to the drugs was assessed by pill counting. Serial monitoring of weight and blood pressure was done at one month interval in all the cases. Blood sugar, fasting lipid profile and waist hip ratio was re-measured at the end of three month. Occurrence of any side effects were carefully noted.

The statistical analysis was performed using SPPS version 16.0 software. Mean weight and blood pressure in the two groups were compared using student $t$ test. The descriptive values below $5 \%(p<0.05)$ were considered statistically significant.

\section{Results}

A total of 68 patients were included in the intent to treat (ITT) analysis. The baseline parameters and findings on initial investigations in these patients are summarized in Table1. These patients were followed up for a period of three months.

Table 1: Baseline parameters of patients in the two groups

\begin{tabular}{|l|l|l|}
\hline \multicolumn{3}{|l|}{ Table 1: Baseline parameters of patients in the two groups } \\
\hline Number of patients(n) & Group I & Group II \\
\hline Mean age(years) $\pm \mathrm{SE}$ & 34 & 34 \\
\hline Male: Female & $45.03 \pm 1.08$ & $44.91 \pm 1.17$ \\
\hline Mean weight $(\mathrm{kg}) \pm \mathrm{SE}$ & $2.5: 1$ & $3.6: 1$ \\
\hline Mean SBP mm Hg $\pm \mathrm{SE}$ & $95.90 \pm 0.77$ & $95.96 \pm 0.72$ \\
\hline Mean DBP mm Hg $\pm \mathrm{SE}$ & $143.41 \pm 0.76$ & $143.59 \pm 0.67$ \\
\hline Mean Fasting blood sugar(mg/dl) $\pm \mathrm{SE}$ & $92.75 \pm 0.42$ & $92.88 \pm 0.39$ \\
\hline Mean Postprandial blood sugar(mg/dl) $\pm \mathrm{SE}$ & $95.91 \pm 0.97$ & $95.88 \pm 0.92$ \\
\hline Mean Total Cholesterol(TC) $\pm \mathrm{SE}(\mathrm{mg} / \mathrm{dl})$ & $144.69 \pm 1.78$ & $145.06 \pm 1.79$ \\
\hline Mean Triglycerides(TG) $\pm \mathrm{SE}(\mathrm{mg} / \mathrm{dl})$ & $196.99 \pm 2.30$ & $196.32 \pm 1.53$ \\
\hline Mean Low Density Lipoprotein(LDL) $\pm \mathrm{SE}(\mathrm{mg} / \mathrm{dl})$ & $183.31 \pm 1.47$ & $183.59 \pm 1.15$ \\
\hline Mean High Density Lipoprotein(HDL) $\pm \mathrm{SE}(\mathrm{mg} / \mathrm{dl})$ & $120.59 \pm 1.01$ & $121.03 \pm 0.89$ \\
\hline Mean waist/hip ratio \pm SE & $43.50 \pm 1.07$ & $43.24 \pm 0.95$ \\
\hline
\end{tabular}

Weight and blood pressure was monitored monthly. The mean reduction of weight, blood pressure (systolic and diastolic) during follow up in the two groups are summarized in Table 2 and depicted graphically in Fig. 1

Table 2: Weight and Blood pressure during follow up in the two groups

\begin{tabular}{|c|c|c|c|c|c|c|}
\hline Variables & Groups & Day 0 & Day 30 & Day 60 & Day 90 & \%change \\
\hline \multirow[t]{2}{*}{ Weight(kg) } & Placebo & $95.96 \pm 0.72$ & $95.89 \pm 0.72$ & $95.80 \pm 0.73$ & $95.63 \pm 0.73$ & $0.3 \%$ \\
\hline & Orlistat & $95.90 \pm 0.77$ & $94.96 \pm 0.86^{\mathrm{a}}$ & $94.07 \pm 0.87^{\mathrm{a}}$ & $93.46 \pm 0.82^{\mathrm{a}}$ & $2.6 \%$ \\
\hline \multirow[t]{2}{*}{$\mathrm{SBP}(\mathrm{mmHg})$} & Placebo & $143.59 \pm 0.67$ & $143.21 \pm 0.58$ & $142.91 \pm 0.68$ & $142.12 \pm 0.67$ & $1.0 \%$ \\
\hline & Orlistat & $143.41 \pm 0.76$ & $142.72 \pm 0.68^{\mathrm{a}}$ & $141.34 \pm 0.70^{\mathrm{a}}$ & $138.91 \pm 0.76^{\mathrm{a}}$ & $3.1 \%$ \\
\hline \multirow[t]{2}{*}{$\mathrm{DBP}(\mathrm{mmHg})$} & Placebo & $94.71 \pm 0.44$ & $94.24 \pm 0.43$ & $93.94 \pm 0.53$ & $93.74 \pm 0.42$ & $1.0 \%$ \\
\hline & Orlistat & $94.91 \pm 0.33$ & $93.16 \pm 0.43^{\mathbf{a}}$ & $92.50 \pm 0.48^{\mathbf{a}}$ & $92.25 \pm 0.39^{\mathrm{a}}$ & $2.8 \%$ \\
\hline
\end{tabular}

$$
\mathrm{a}=\mathrm{p}<0.05 \text { in comparison with placebo }
$$

At baseline (day 0), there was no significant difference in mean weight and blood pressure in the two groups. During follow up of three months significant reduction of these parameters was observed in group I as compared to group II evident from the first follow up visit. 
At the end of three months, there was a significant change in mean weight with Orlistat (2.6\%) as compared to placebo $(0.3 \%)(-2.44 \mathrm{~kg}$ versus $0.33 \mathrm{~kg})$.

Figure 1: Weight reduction during follow up in the two groups

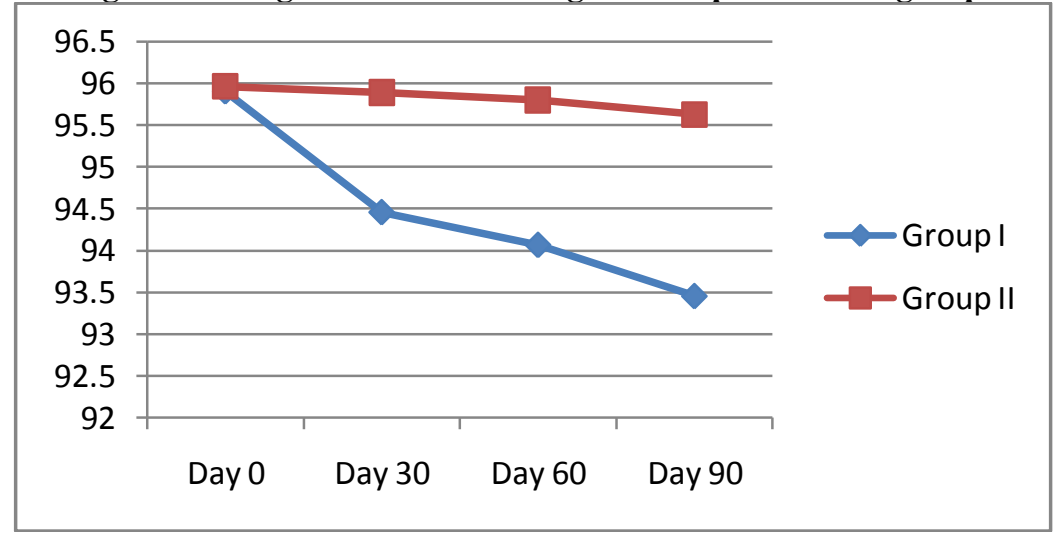

Mean systolic blood pressure was reduced to a significantly greater degree with Orlistat $(3.1 \%)$ compared to placebo $(1 \%)(-4.5 \mathrm{~mm} \mathrm{Hg}$ versus $-1.47 \mathrm{~mm} \mathrm{Hg}, \mathrm{p}<0.05)$ at the end of three months. Similarly, reductions in mean diastolic blood pressure was greater with Orlistat $(2.8 \%)$ than with placebo $(1 \%)(-2.66$ $\mathrm{mm} \mathrm{Hg}$ versus $-0.97 \mathrm{mmHg} ; \mathrm{p}<0.05)$ at the end of three months of therapy.

Blood sugar (fasting and postprandial), fasting lipid profile and waist hip ratio was re-measured at the end of three months. The mean reduction of blood sugar, fasting lipid profile and waist hip ratio during follow up in the two groups are summarized in Table 3.

Table 3: Blood sugar and lipid profile during follow up in the two groups

\begin{tabular}{|c|c|c|c|c|}
\hline Variables & Groups & Day 0 & Day 90 & $\begin{array}{l}\text { Percentag } \\
\text { e change }\end{array}$ \\
\hline \multirow{2}{*}{$\begin{array}{l}\text { Fasting Blood sugar } \\
(\mathrm{mg} / \mathrm{dl})\end{array}$} & Placebo & $95.88 \pm 0.92$ & $94.94 \pm 0.92$ & $1.0 \%$ \\
\hline & Orlistat & $95.91 \pm 0.97$ & $93.88 \pm 0.98^{\mathrm{a}}$ & $2.1 \%$ \\
\hline \multirow{2}{*}{$\begin{array}{l}\text { Postprandial Blood } \\
\text { sugar(mg/dl) }\end{array}$} & Placebo & $145.06 \pm 1.79$ & $144.15 \pm 1.81$ & $0.6 \%$ \\
\hline & Orlistat & $144.69 \pm 1.78$ & $142.75 \pm 1.81^{\mathrm{a}}$ & $1.3 \%$ \\
\hline \multirow{2}{*}{$\begin{array}{l}\text { Total Cholesterol } \\
(\mathrm{mg} / \mathrm{dl})\end{array}$} & Placebo & $196.32 \pm 1.53$ & $196.21 \pm 1.57$ & $0.6 \%$ \\
\hline & Orlistat & $196.94 \pm 2.30$ & $195.84 \pm 2.31^{\mathrm{a}}$ & $0.1 \%$ \\
\hline \multirow[t]{2}{*}{ HDL (mg/dl) } & Placebo & $43.24 \pm 0.95$ & $43.15 \pm 0.90$ & $0.2 \%$ \\
\hline & Orlistat & $43.50 \pm 1.07$ & $43.37 \pm 1.06^{b}$ & $0.6 \%$ \\
\hline \multirow[t]{2}{*}{ LDL (mg/dl) } & Placebo & $121.03 \pm 0.89$ & $120.76 \pm 0.88$ & $0.2 \%$ \\
\hline & Orlistat & $120.59 \pm 1.01$ & $119.41 \pm 1.06^{\mathrm{a}}$ & $1.0 \%$ \\
\hline \multirow[t]{2}{*}{ VLDL(mg/dl) } & Placebo & $28.38 \pm 0.75$ & $28.24 \pm 0.71$ & $0.5 \%$ \\
\hline & Orlistat & $28.56 \pm 0.79$ & $27.59 \pm 0.76^{\mathrm{a}}$ & $3.4 \%$ \\
\hline \multirow[t]{2}{*}{$\mathrm{TG}(\mathrm{mg} / \mathrm{dl})$} & Placebo & $183.59 \pm 1.15$ & $183.26 \pm 1.16$ & $0.2 \%$ \\
\hline & Orlistat & $183.31 \pm 1.47$ & $182.66 \pm 1.48^{\mathrm{a}}$ & $0.4 \%$ \\
\hline \multirow[t]{2}{*}{ WHR } & Placebo & $0.920 \pm 0.003$ & $0.919 \pm 0.003$ & $0.1 \%$ \\
\hline & Orlistat & $0.917 \pm 0.004$ & $0.906 \pm 0.004^{\mathrm{a}}$ & $1.2 \%$ \\
\hline
\end{tabular}

$\mathrm{a}=\mathrm{p}<0.05$ in comparison with placebo, $\mathrm{b}=\mathrm{p}>0.05$ in comparison with placebo

As evident from table 3, at baseline (day 0), there was no significant difference in these parameters in the two groups. During follow up period of three months, group I showed significantly more reduction in blood sugar, lipid profile and waist hip ratio as compared to group II.

The most common adverse effect observed in group I patients included oily stool (37.5\%), diarrhoea $(18.8 \%)$, nausea $(18.8 \%)$ and vomiting $(12.7 \%)$. The proportion of diarrhoea and oily stool were found to be significantly $(\mathrm{p}<0.05)$ higher in group I as compared to group II.

\section{Discussion}

This study evaluates the effect of Orlistat, a lipase inhibitor, on blood pressure in overweight /obese hypertensive individuals. In conjunction with a reduced-calorie diet, treatment with $120 \mathrm{mg}$ of Orlistat twice daily for 90 days significantly decreased blood pressure (systolic and diastolic), weight, blood sugar(fasting and postprandial), fasting lipid profile and waist hip ratio as compared to placebo.This effect is probably due to the decrease in the absorption of fat and its associated calories. ${ }^{6}$ Gastrointestinal tract adverse effects were observed more frequently with Orlistat. 
In previous studies, Orlistat has been shown to cause significant and sustained reduction in weight, blood pressure, blood sugar, lipid profile and waist hip ratio in overweight or obese adults when given at a dose of $120 \mathrm{mg} 3$ times daily and combined with a mildly reduced-calorie diet for a longer duration of at least one year. $^{7,8,9}$

In the current study, Orlistat in a lesser dose of $120 \mathrm{mg}$ twice daily for a lesser time (three months) was associated with a statistically significant decrease in blood pressure, weight, blood sugar, lipid profile and waist hip ratio in contrast to the placebo group. In this three months trial, Orlistat did not raise any safety issues, and the adverse event profiles except for gastrointestinal tract adverse events as compared to placebo group.

\section{Conclusion}

We conclude that Orlistat $120 \mathrm{mg}$ twice daily for 90 days, in conjunction with a reduced-calorie diet, significantly improves blood pressure and other cardiovascular risk factors in obese hypertensive patients and should be recommended in every obese hypertensive patient so that the cost and potential adverse affects of lifelong antihypertensive therapy can be avoided.

\section{References}

[1]. World health organization, Obesty and overweight, Factsheet no.-311,September 2006

[2]. S MacMahon,., J Cutler, E Brittain,, M Higgins, Obesity and hypertension: epidemiological and clinical issues, European Heart Journal, 8(Suppl b), 1987,57-70

[3]. W B Kannel, Blood pressure as a cardiovascular risk factor. prevention and treatment, Journal of the American Medical Association ,275,1996,1571-1576.

[4]. H B Hubert, M Feinleib , P M McNamara et.al. Obesity as an independent risk factor for cardiovascular disease: a 26-year followup of participants in the Framingham Heart Study, Circulation 67, 1983, 969-977.

[5]. A R Dyer,, P Elliot,, The INTERSALT study: relations of body mass index to blood pressure, Journal of Human Hypertension,3,1989,299-308.

[6]. J Zhi, T E Mulligan, J B Hauptman, Long-term systemic exposure of Orlistat, a lipase inhibitor, and its metabolites in obese patients, Journal of Clinical Pharmacology, 39, 1999,41-46

[7]. A M Sharma, A Golay, Effect of Orlistat induced weight loss on blood pressure and heart rate in obese patients with hypertension, Journal of hypertension, 20(9),2002 Sep,1873-8

[8]. L Sjöström, A Rissanen, T Andersen et al. European Multicenter Orlistat Study Group, Randomised placebo-controlled trial of orlistat for weight loss and prevention of weight regain in obese subjects, Lancet, 35, 1998, 2167-172

[9]. M Krempf, J P Louvet, H Allanic et.al..Weight reduction and long term maintenance after 18 months treatment with Orlistat for obesity, Int J Obes Relat Metab Disord. 27, 2003, 591-597 